\title{
Current overview of myasthenia gravis and experience in China
}

\author{
Jun Guo, Dan Dang, Hong-Zeng Li, Zhu-Yi Li \\ Department of Neurology, Tangdu Hospital, Fourth Military Medical University, Xi'an 710038, Shaanxi, China.
}

\section{A B S T R A C T}

Myasthenia gravis (MG) is an acquired autoimmune disease affecting synaptic transmission via the neuromuscular junction mainly due to the presence of auto-antibodies targeting acetylcholine receptors. Ocular or generalized MG is clinically diagnosed when the extra-ocular muscles or other muscle groups beyond the extra-ocular muscles are involved. MG occurs in both sexes at any ages from all races but shows a wide variability in incidence and prevalence. Differences in clinical phenotypes of MG patients between West and East countries have been observed. Herein, we review the current concept on epidemiology, classification, and generalized progression in MG, mainly focusing on the differential features from mainland China.

Key words: Classification, epidemiology, generalization, myasthenia gravis

\section{INTRODUCTION}

Myasthenia gravis (MG) is known as an autoimmune disease mainly mediated by auto-antibodies against the acetylcholine receptors (AChR) between the synaptic space of the skeletal muscles, leading to an impairment of the neuromuscular transmission and corresponding clinical symptoms such as fluctuating muscle weakness and fatigability. ${ }^{[1]}$ According to clinical symptoms, MG is divided into ocular MG and generalized MG. Secondary generalization of clinical symptoms is common in MG, resulting in a poor prognosis for patients and a tremendous burden for families and society. ${ }^{[2]}$ Although epidemiological studies have shown that all the races worldwide can be affected, differences between Caucasian and Asian patients were found in relation to clinical phenotypes ${ }^{[3-5]}$ In this mini-review, we address the current concepts of MG, including epidemiology, classification of clinical subtypes, and secondary generalization. We also focus on the different clinical features of MG in China.

\begin{tabular}{|c|c|}
\hline \multicolumn{2}{|c|}{ Access this article online } \\
\hline Quick Response Code: & \multirow[b]{2}{*}{$\begin{array}{l}\text { Website: } \\
\text { www.nnjournal.net }\end{array}$} \\
\hline BD & \\
\hline & $\begin{array}{l}\text { DOI: } \\
10.4103 / 2347-8659.143664\end{array}$ \\
\hline
\end{tabular}

\section{EPIDEMIOLOGY}

It is well known that MG occurs worldwide affecting both males and females at any ages as shown in an epidemiological study with a large sample size. ${ }^{[6]}$ However, the incidence and prevalence of MG are characterized by marked variation, depending on the time and/or the location of studies. A national epidemiological study in Australia has shown that the annual crude incidence and prevalence rates of MG were 24.9 and 117.1/million, respectively. ${ }^{[7]}$ Other two population-based studies have been conducted in Taiwan and Norway. The reported annual incidence and prevalence of MG were 21 and 84-140/million in Taiwan, ${ }^{[8]}$ and 16 and 131/million in Norway. ${ }^{[9]}$ Moreover, the estimated annual incidence rate of MG is 30/million in central London, ${ }^{[10]}$ 24/million in Ferrara province of Italy, ${ }^{[11]}$ and 21.3/1 million in Barcelona of Spain. ${ }^{[12]}$ Unfortunately, no national population-based epidemiological studies of MG have been conducted in mainland China. To obtain pooled data from a larger sample, Carr et al. ${ }^{[6]}$ have collated 55 studies performed between 1950 and 2007, representing 1.7 billion population-years. By utilizing the meta-analysis, they have estimated that the annual incidence and prevalence rates of MG were 5.3 (range: 1.7-21.3) and 77.7/million (15-179), respectively.

The onset of MG may be influenced by sex and age. Regardless of age, the crude incidences of females

Corresponding Author: Dr. Zhu-Yi Li, Department of Neurology, Tangdu Hospital, Fourth Military Medical University, Xi'an 710038, Shaanxi, China. E-mail: lizhuyi@fmmu.edu.cn 
and males in Australia are 27.9 and 21.9/1 million, respectively, with a female predominance. ${ }^{[6]} \mathrm{A}$ similar tendency was shown in Taiwan where the incidence ratio of males to females is $0.68 .{ }^{[8]}$ However, three studies with large sample sizes showed a nearly equal incidence for both sexes in mainland China. ${ }^{[13-15]}$ Considering age and sex, the occurrence of MG exhibits a bimodal fashion. Below 40 years of age, the ratio of female to male is nearly $3: 1$; however, during puberty and between 40 and 50 years, the incidence rate is roughly equal. Over 50 years, MG is more common in males, with a ratio of 3:2.[16] Osserman and Genkins have observed two peaks of incidence in MG, with the first one at 20-40 years old and the second one at 40-60 years old, ${ }^{[17]}$ but in another study, the second peak of incidence was determined at ages of 60-80 years. ${ }^{[18]}$ Childhood MG (onset < 15 years) is not common in North America and Europe, comprising 10-15\% of MG cases $^{[19]}$ However, MG occurs during childhood in up to $50 \%$ of Chinese patients, mainly with pure ocular symptoms. ${ }^{[5,13]}$

\section{CLASSIFICATION OF MYASTHENIA GRAVIS}

Myasthenia gravis is a heterogeneous disorder with variable clinical symptoms because of the different location of involved neuromuscular junction. Up to now, the most widely accepted classification is the Myasthenia Gravis Foundation of America (MGFA) Clinical Classification, ${ }^{[20]}$ a Task Force that was formed by the Medical Scientific Advisory Board of MGFA since 1997. It was designed to identify subtypes of MG patients with distinct clinical features or severity of disease indicating different prognosis or treatment response, but it is not used to evaluate the outcome. According to MGFA, MG can be divided into 5 main classes and several subclasses [Table 1].

Another classification of MG is based on clinical symptoms, age of onset, auto-antibody profile and thymic histology. ${ }^{[21-24]}$ Briefly, MG patients are divided into six subtypes: ocular MG, early-onset MG, late-onset MG, thymoma-associated MG, muscle-specific tyrosine kinase (MuSK) antibody-associated MG and seronegative MG. ${ }^{[25,26]}$ Early-onset patients have several clinical characteristics such as female predominance, generalized involvement, no evidence of thymoma and presence of anti-AChR antibodies. A predominance of thymic hyperplasia is observed in this subtype. However, late-onset MG patients are more common among males. These patients have generalized symptoms, and usually have normal or atrophic thymus. ${ }^{[27]}$ The titer of anti-AChR antibodies is usually lower in late-onset subtype than that in the early-onset subtype, and antibodies against titin and ryanodine receptor are detected in about $50 \%$ of such patients. ${ }^{[23]}$ Thymoma-associated MG involves MG patients with thymoma regardless of the extent of muscular involvement, accounting for about $10-15 \%$ of all MG patients. Male and female patients are equally common in this subtype, and MG occurs at any age with a peak onset age of 50 years. ${ }^{[28,29]}$ In seronegative MG patients, anti-AChR and anti-MuSK antibodies are undetectable. Clinical features such as variable age of onset, lack of thymoma and variable extent and severity of muscular involvement are also found. ${ }^{[30]}$ The detailed characteristics of all subtypes are listed in Table 2.

\begin{tabular}{|c|c|}
\hline Type & Characteristics \\
\hline Class I & $\begin{array}{l}\text { Any ocular muscle weakness, possible ptosis, no } \\
\text { evidence of muscle weakness elsewhere }\end{array}$ \\
\hline Class II & $\begin{array}{l}\text { Ocular muscle weakness of any severity, mild } \\
\text { weakness of other muscles }\end{array}$ \\
\hline Class Ila & $\begin{array}{l}\text { Predominantly limb and/or axial muscles weakness, } \\
\text { possible lesser involvement of bulbar muscles }\end{array}$ \\
\hline Class IIb & $\begin{array}{l}\text { Predominantly bulbar and/or respiratory muscles } \\
\text { weakness, possible lesser or equal involvement of limb } \\
\text { and/or axial muscles }\end{array}$ \\
\hline Class III & $\begin{array}{l}\text { Ocular muscle weakness of any severity, moderate } \\
\text { weakness of other muscles }\end{array}$ \\
\hline Class IIla & $\begin{array}{l}\text { Predominantly limb and/or axial muscles weakness, } \\
\text { possible lesser involvement of bulbar muscles }\end{array}$ \\
\hline Class IIIb & $\begin{array}{l}\text { Predominantly bulbar and/or respiratory muscles } \\
\text { weakness, possible lesser or equal involvement of limb } \\
\text { and/or axial muscles }\end{array}$ \\
\hline Class IV & $\begin{array}{l}\text { Ocular muscle weakness of any severity, severe } \\
\text { weakness of other muscles }\end{array}$ \\
\hline Class IVa & $\begin{array}{l}\text { Predominantly limb and/or axial muscles weakness, } \\
\text { possible lesser involvement of bulbar muscles }\end{array}$ \\
\hline Class IVb & $\begin{array}{l}\text { Predominantly bulbar and/or respiratory muscles } \\
\text { weakness, possible lesser or equal involvement of limb } \\
\text { and/or axial muscles }\end{array}$ \\
\hline Class V & $\begin{array}{l}\text { Intubation with or without mechanical ventilation } \\
\text { except when employed during routine postoperative } \\
\text { management, the use of feeding tube without } \\
\text { intubation places the patient in class IVb }\end{array}$ \\
\hline
\end{tabular}

\begin{tabular}{|c|c|}
\hline Subtypes & Characteristics \\
\hline Ocular MG & $\begin{array}{l}\text { Purely ocular symptoms, no evidence of } \\
\text { thymoma, adult in America and Europe, } \\
\text { childhood in Asia, anti-AChR antibody positive } \\
\text { in } 50 \%\end{array}$ \\
\hline Early-onset MG & $\begin{array}{l}\text { Age of onset }<50 \text { years, thymic hyperplasia, } \\
\text { usually females, antibodies against AChR }\end{array}$ \\
\hline Late-onset MG & $\begin{array}{l}\text { Age of onset }>50 \text { years, normal or atrophic } \\
\text { thymus, mainly males, presence of antibodies } \\
\text { against AChR, titin, RyR }\end{array}$ \\
\hline $\begin{array}{l}\text { Thymoma- } \\
\text { associated MG }\end{array}$ & $\begin{array}{l}\text { Age of onset between } 40 \text { and } 60 \text { years, thymic } \\
\text { neoplasia, antibodies against AChR, titin, RyR } \\
\text { and voltage-gated } \mathrm{K}^{+} \text {channel subfamily A } \\
\text { member } 4 \text { (KCNA4) }\end{array}$ \\
\hline $\begin{array}{l}\text { MuSK antibody- } \\
\text { associated MG }\end{array}$ & $\begin{array}{l}\text { Onset age }<40 \text { years in most patients, normal } \\
\text { thymus, antibodies against MuSK }\end{array}$ \\
\hline $\begin{array}{l}\text { Seronegative } \\
\text { MG }\end{array}$ & $\begin{array}{l}\text { Variable muscular involvement and severity, } \\
\text { variable age of onset, thymic hyperplasia in } \\
\text { some patients, no detectable antibodies against } \\
\text { AChR and MuSK }\end{array}$ \\
\hline
\end{tabular}
receptors; RyR: ryanodine receptor 
Modified osserman classification is also commonly used to distinguish subtype of MG patients and indicates the different prognosis and treatment response. This classification has been frequently recommended and widely used over the past several decades in China. Although the modified Osserman classification is based on clinical symptoms, impact on work and daily life, course of disease and treatment response, it is extremely challenging to take into account the prognosis and disability of patients. Moreover, this classification does not contain MG-associated auto-antibodies and low-frequency repetitive nerve stimulation (RNS) tests.

In 1997, Wang et al. ${ }^{[31]}$ proposed a new clinical absolute and relative score system for MG in Chinese patients. The absolute scoring system consists of 8 items: ptosis, palpebra superior fatigability, disability of ocular motion, fatigability of the upper and lower extremity muscles, disability of facial muscles, chewing difficulties, dysphagia and disability of respiratory muscles, with a score of each item ranging from 0 (normal) to 4 (severe dysfunction). The relative scores are obtained by subtracting the pretreatment scores from the posttreatment scores and then dividing the results by the pretreatment scores. Several studies have proven that the clinical absolute and relative scoring system has good reliability and sensitivity to evaluate the disabilities in MG patients ${ }^{[31,32]}$ and the clinical absolute and relative system is officially recommended by the Consensus of Chinese Experts in the Diagnosis and Treatment for Myasthenia Gravis. ${ }^{[33]}$

\section{SECONDARY GENERALIZATION}

Generalization of clinical symptoms is an important hallmark of MG patients. Ocular MG is termed when weakness is only limited to the extra-ocular muscles for $>2$ years, ${ }^{[34,35]}$ while generalized MG is defined as an extension of weakness beyond ocular muscles. The involvement of muscles is confirmed mainly by clinical presentations. Due to the different involvement of muscle groups, clinical presentation varies from fluctuating extra-ocular muscular weakness to respiratory failure. Secondary generalization mainly occurs during the first 2 years $^{[16,36]}$ and sometimes leads to the deterioration of prognosis including death.

It is well-known that ocular muscle weakness is the most common initial symptoms of MG, occurring in approximately $85 \%$ of patients. About $50 \%$ of these ocular MG patients may progress to generalized MG within 6 months after onset, $80 \%$ of patients within 1 -year, and $90 \%$ of patients after 3 years. Only $10 \%$ of MG patients do not progress to secondary generalization throughout lifetime. ${ }^{[2]}$ Another published study has reported that up to $65 \%$ of MG patients initially show ocular muscle involvements, and generalization of symptoms occur in only $44 \%$ of patients within 2 years. ${ }^{[37]}$ In a follow-up study including 96 Thai patients with ocular MG, only 15 patients (15.6\%) developed generalized symptoms within 2 years from the initial diagnosis. ${ }^{[38]}$ It is to be noted that about $50 \%$ of Chinese MG patients present with pure ocular manifestations during their entire lifetime, ${ }^{[5]}$ with a relatively lower rate of generalization. Recently, Jing et $a .^{\left[{ }^{[39]}\right.}$ have also reported that only $26 \%$ of Chinese patients with ocular MG develop into generalized MG during a 13-year follow-up period. These differences in the rate of secondary generalization might be attributed to the difference in race, severity of disease and early treatment with immunosuppressive drugs, especially corticosteroids. ${ }^{[38,40]}$

Given the poor prognosis of generalized MG, it is important to detect the risk factors of secondary generalization in those MG patients with initial ocular presentations. Previous studies have revealed that onset age $>15$ years, presence of thymoma, early corticosteroids therapy and abnormal RNS results on stimulating proximal limb muscles are predictors for the development of generalized MG. ${ }^{[39,41-43]}$ Our recent study has shown that disease onset during adulthood and RNS abnormality of the facial nerve predict the progression from ocular to generalized MG while course of the disease is inversely correlated with secondary generalization (unpublished data). In a senior population, the ocular MG patients with anti-AChR antibodies, antistriated muscle antibodies, abnormal RNS findings and abnormal single fiber electromyography tend to develop generalized MG. ${ }^{[44]}$ However, other studies have demonstrated that none of these factors significantly predict development of generalized MG in younger populations. ${ }^{[2,45,46]}$ Although similar results have been obtained in some studies, there are also some limitations such as the use of retrospective methodology, incomplete clinical data, small sample size and single hospital or center. Larger-sample, multi-center, prospective studies are needed to obtain more convincing risk factors for generalization of ocular MG.

\section{ACKNOWLEDGMENTS}

This work was supported by the National Natural Science Foundation of China (Nos. 31200665, 31270952 and 81301069).

\section{REFERENCES}

1. Vincent A, Palace J, Hilton-Jones D. Myasthenia gravis. Lancet 2001;357:2122-8.

2. Bever CT Jr, Aquino AV, Penn AS, Lovelace RE, Rowland LP. Prognosis of ocular myasthenia. Ann Neurol 1983;14:516-9. 
3. McGrogan A, Sneddon S, de Vries CS. The incidence of myasthenia gravis: a systematic literature review. Neuroepidemiology 2010;34:171-83.

4. Kawaguchi N, Kuwabara S, Nemoto Y, Fukutake T, Satomura Y, Arimura K, Osame M, Hattori T. Treatment and outcome of myasthenia gravis: retrospective multi-center analysis of 470 Japanese patients, 1999-2000. J Neurol Sci 2004;224:43-7.

5. Zhang X, Yang M, Xu J, Zhang M, Lang B, Wang W, Vincent A Clinical and serological study of myasthenia gravis in $\mathrm{HuBei}$ Province, China. J Neurol Neurosurg Psychiatry 2007;78:386-90.

6. Carr AS, Cardwell CR, McCarron PO, McConville J. A systematic review of population based epidemiological studies in myasthenia gravis. BMC Neurol 2010;10:46.

7. Gattellari M, Goumas C, Worthington JM. A national epidemiological study of myasthenia gravis in Australia. Eur $J$ Neurol 2012;19:1413-20.

8. Lai $\mathrm{CH}$, Tseng HF. Nationwide population-based epidemiological study of myasthenia gravis in Taiwan. Neuroepidemiology 2010;35:66-71.

9. Andersen JB, Engeland A, Owe JF, Gilhus NE. Myasthenia gravis requiring pyridostigmine treatment in a national population cohort. Eur J Neurol 2010;17:1445-50

10. MacDonald BK, Cockerell OC, Sander JW, Shorvon SD. The incidence and lifetime prevalence of neurological disorders in a prospective community-based study in the UK. Brain 2000;123:665-76

11. Casetta I, Groppo E, De Gennaro R, Cesnik E, Piccolo L, Volpato S, Granieri E. Myasthenia gravis: a changing pattern of incidence. J Neurol 2010;257:2015-9.

12. Aragonès JM, Bolíbar I, Bonfill X, Bufill E, Mummany A, Alonso F, Illa I. Myasthenia gravis: a higher than expected incidence in the elderly. Neurology 2003;60:1024-6.

13. Liu WB, Men LN, He XT, Xia Q, Huang RX. Clinical analysis on 1520 patients with myasthenia gravis in southern China. Chin $J$ Neuroimmunol Neurol 2006;13:326-30.

14. Xu JZ, Yang MS, Li BH, Jiang HP, Zhang RX, Xu SB. Myasthenia gravis: clinical study in 2385 patients. Chin J Neurol 1999;32:347-50.

15. Wang W, Chen YP, Wang ZK, Wei DN, Yin L. A cohort study on myasthenia gravis patients in China. Neurol Sci 2013;34:1759-64.

16. Grob D, Brunner N, Namba T, Pagala M. Lifetime course of myasthenia gravis. Muscle Nerve 2008;37:141-9.

17. Osserman KE, Genkins G. Studies in myasthenia gravis: review of a twenty-year experience in over 1200 patients. Mt Sinai J Med 1971;38:497-537

18. Thanvi BR, Lo TC. Update on myasthenia gravis. Postgrad Med J 2004;80:690-700.

19. Phillips LH 2nd. The epidemiology of myasthenia gravis. Ann NY Acad Sci 2003;998:407-12.

20. Jaretzki A 3rd, Barohn RJ, Ernstoff RM, Kaminski HJ, Keesey JC, Penn AS, Sanders DB. Myasthenia gravis: recommendations for clinical research standards. Task Force of the Medical Scientific Advisory Board of the Myasthenia Gravis Foundation of America. Neurology 2000;55:16-23.

21. Compston DA, Vincent A, Newsom-Davis J, Batchelor JR. Clinical, pathological, HLA antigen and immunological evidence for disease heterogeneity in myasthenia gravis. Brain 1980;103:579-601.

22. Kuks JB, Limburg PC, Horst G, Oosterhuis HJ. Antibodies to skeletal muscle in myasthenia gravis. Part 2. Prevalence in non-thymoma patients. J Neurol Sci 1993;120:78-81.

23. Romi F, Skeie GO, Aarli JA, Gilhus NE. Muscle autoantibodies in subgroups of myasthenia gravis patients. JNeurol 2000;247:369-75.

24. Agius MA, Richman DP, Fairclough RH, Aarli J, Gilhus NE, Romi F. Three forms of immune myasthenia. Ann N Y Acad Sci 2003;998:453-6.

25. Gilhus NE, Owe JF, Hoff JM, Romi F, Skeie GO, Aarli JA. Myasthenia gravis: a review of available treatment approaches. Autoimmune Dis 2011;2011:847393

26. Jayam Trouth A, Dabi A, Solieman N, Kurukumbi M, Kalyanam J. Myasthenia gravis: a review. Autoimmune Dis 2012;2012:874680.
27. Myking AO, Skeie GO,Varhaug JE, Andersen KS, Gilhus NE, Aarli JA. The histomorphology of the thymus in late onset, non-thymoma myasthenia gravis. Eur J Neurol 1998;5:401-5.

28. Skeie GO, Romi F. Paraneoplastic myasthenia gravis: immunological and clinical aspects. Eur J Neurol 2008;15:1029-33

29. Evoli A, Minisci C, Di Schino C, Marsili F, Punzi C, Batocchi AP, Tonali PA, Doglietto GB, Granone P, Trodella L, Cassano A, Lauriola L. Thymoma in patients with MG: characteristics and long-term outcome. Neurology 2002;59:1844-50.

30. Romi F, Aarli JA, Gilhus NE. Seronegative myasthenia gravis: disease severity and prognosis. Eur J Neurol 2005;12:413-8.

31. Wang SY, Xu XH, Sun H, Han X, Zhang H, Guo H. A clinical absolute and relative score system for myasthenia gravis. Chin $J$ Neurol 1997;30:87-90

32. Chen P, Wang YP, Liu JJ, Dang GX. Application of clinical absolute and relative score system in diagnosis for myasthenia gravis. $J$ Fourth Mil Med Univ 2008;29:566-8.

33. Li ZY, Hu XQ, Neuroimmunology Branch of Chinese Society for Immunology; Neuroimmunology Branch, Chinese Society of Neurology, Chinese Medical Association. Consensus of Chinese experts in the diagnosis and treatment for myasthenia gravis. Chin J Neuroimmunol Neurol 2012;19:401-8.

34. Beekman R, Kuks JB, Oosterhuis HJ. Myasthenia gravis: diagnosis and follow-up of 100 consecutive patients. JNeurol 1997;244:112-8.

35. Keesey JC. Clinical evaluation and management of myasthenia gravis. Muscle Nerve 2004;29:484-505.

36. Kupersmith MJ, Latkany R, Homel P. Development of generalized disease at 2 years in patients with ocular myasthenia gravis. Arch Neurol 2003;60:243-8

37. Schlezinger NS, Fairfax WA. Evaluation of ocular signs and symptoms in myasthenia gravis. Arch Ophthalmol 1959;62:985-90.

38. Leeamornsiri S, Chirapapaisan N, Chuenkongkaew W. Clinical profiles of Thai patients with ocular myasthenia gravis in Siriraj Hospital. J Med Assoc Thai 2011;94:1117-21.

39. Jing J, Zhang XJ, Yu L, Chen RL, Qin NN, Ma S. Factors affecting the progression from ocular to generalized myasthenia gravis. Chin J Neurol 2014;47:21-5.

40. Yang ZX, Xiong H, Zhang YH, Bao XH, Jiang YW, Wu Y, Wang S, Chang XZ, Qin J, Lin Q, Wu XR. Clinical characteristics and follow-up management of 135 children with myasthenia gravis. Beijing Da Xue Xue Bao 2011;43:455-9.

41. Hong YH, Kwon SB, Kim BJ, Kim BJ, Kim SH, Kim JK, Park KS Park KJ, Sung JJ, Sohn EH, Lee YB, Jeong D, Joo IS, Choi BO, Choi YC, Korean Research Group for Neuromuscular D. Prognosis of ocular myasthenia in Korea: a retrospective multicenter analysis of 202 patients. J Neurol Sci 2008;273:10-4.

42. Kupersmith MJ. Ocular myasthenia gravis: treatment successes and failures in patients with long-term follow-up. $J$ Neurol 2009;256:1314-20.

43. Guan YZ, Cui LY, Liu MS, Wang H, Zhang JB, Li YF. Progression from ocular to generalized myasthenia gravis in adults. Chin JNeurol 2012;45:866-8

44. Allen JA, Scala S, Jones HR. Ocular myasthenia gravis in a senior population: diagnosis, therapy, and prognosis. Muscle Nerve 2010;41:379-84.

45. Sommer N, Sigg B, Melms A, Weller M, Schepelmann K, Herzau V Dichgans J. Ocular myasthenia gravis: response to long-term immunosuppressive treatment. $J$ Neurol Neurosurg Psychiatry 1997;62:156-62.

46. Weinberg DH, Rizzo JF 3rd, Hayes MT, Kneeland MD, Kelly JJ Jr. Ocular myasthenia gravis: predictive value of single-fiber electromyography. Muscle Nerve 1999;22:1222-7.

Cite this article as: Guo J, Dang D, Li HZ, Li ZY. Current overview of myasthenia gravis and experience in China. Neuroimmunol Neuroinflammation 2014;1(3):127-30.

Source of Support: Nil. Conflict of Interest: No.

Received: 05-08-2014; Accepted: 16-09-2014 